\title{
Metodología para valoración financiera de PYMES colombianas utilizando flujos de efectivo ${ }^{1}$
}

\author{
Methodology for financial valuation of SME's in Colombia using cash flows
}

Recibido: 2 de marzo de 2018 - Revisado: 4 de julio de 2018 - Aceptado: 08 de agosto de 2018.

\author{
Ing. Mauricio Tovar Posso ${ }^{2}$ \\ Ing. Ivonne Tatiana Muñoz Martínez ${ }^{3}$
}

\begin{abstract}
Resumen
En este artículo se diseña y desarrolla un modelo para valorar financieramente pequeñas y medianas empresas (PYMES) colombianas, que se encuentren en marcha y no coticen en Bolsa. Se utiliza la metodología de Flujos de Efectivo Descontados que utiliza como datos de entrada los estados financieros históricos, como el Estado de la Situación Financiera, el Estado de Resultados y el Flujo de Efectivo Libre, la inclusión de algunas variables macroeconómicas y una tasa de descuento apropiada, para poder estimar los valores presentes tanto de los Flujos de Efectivo Libres proyectados como del valor residual de la empresa, que se utilizan para determinar el Valor Financiero Total de una Pyme, y se convierte en información clave para la toma de decisiones financieras ante una posible negociación de compra o venta.
\end{abstract}

\section{Palabras clave}

Valoración financiera de empresas, Metodología de Flujos de Efectivo Descontados, PYMEs colombianas.

\begin{abstract}
In this paper a model is designed and developed to value financially small and medium enterprises (SME's) in Colombia, which are operating and that are not publicly traded. The Discounted Cash Flow methodology is used, which uses historical financial statements as input, such as the Balance Sheet, the Income Statement and the Free Cash Flow Statement the inclusion of some macroeconomic variables and an appropriate discount rate, to be able to estimate the present values of both the projected Free Cash Flows and the residual value of the company, which are used to determine the Total Financial Value of a SME, and becomes key information for making financial decisions before a possible negotiation of purchase o sale.
\end{abstract}

\section{Keywords}

Financial Valuation of Companies, Discounted Cash Flow methodology, Colombian SME's.

\footnotetext{
${ }^{1}$ Artículo de reflexión que presenta resultados de investigación desde una perspectiva analítica e interpretativa sobre el tema de la valoración de empresas en PyMEs colombianas.

${ }^{2}$ Estudiante de Maestría en Gestión de Organizaciones de la Universidad Central de Bogotá. Docente de la Universidad Central de Bogotá. Especialista en Logística Comercial Nacional e Internacional de la Universidad Jorge Tadeo Lozano en Bogotá. Ingeniero industrial de la Universidad Católica de Colombia. Correo electrónico: mtovarp1@ucentral.edu.co. (10) https://orcid.org/0000-0002-32339397

3 Magíster en Administración Universidad Nacional de Colombia en Bogotá. Especialista en Finanzas Universidad de los Andes. Ingeniera Industrial de la Universidad Incca de Colombia. Directora (e) Departamento de Administración de Empresas Universidad Central en Bogotá. Docente Investigadora Integrante del Grupo de Investigación en Gestión de Organizaciones UC-GIGO de la Universidad Central. Correo electrónico: imunozm1@ucentral.edu.co.

fich https://orcid.org/0000-0002-56834552

Para citar este artículo use: Tovar, M. y Muñoz, I. (2018). Metodología para valoración financiera de PyMEs colombianas utilizando flujos de efectivo. Civilizar, 18(35), 139-162. doi: 10.22518/usergioa/jour/ccsh/2018.2/ a11
} 


\section{Introducción}

Dado el interés en conocer cuál es el valor real de un negocio, el presente documento busca ser una guía para PYMEs colombianas en marcha, de cualquier sector, interesadas en determinar de una manera sencilla y rápida dicho valor, utilizando una metodología basada en la generación de valor a través del tiempo, que entrega un rango de valores que serán punto de partida ante una posible negociación que se quiera hacer con la empresa, teniendo en cuenta el entorno de la misma.

En la primera parte del documento, se identifica que las PyMEs colombianas no cuentan con un modelo o metodología, que les permita obtener su valor. Posteriormente se encuentra el marco teórico, en el cual se indagan diferentes conceptos alrededor de la valoración de empresas y cómo pueden aplicarse a las Pymes. Finalmente, se propone un procedimiento paso a paso para determinar el valor de las pequeñas y medianas empresas.

Teniendo en cuenta las características de las Pymes colombianas y desde la gestión de las organizaciones, sería justificable contribuir con el diseño y desarrollo de un modelo que les indique cómo llegar a determinar el valor de la PyME de forma sencilla y periódica, para así lograr la consecución de sus objetivos financieros y mejorar su gestión empresarial para una toma de decisiones responsable y estratégica, a través de un método conocido como Flujos de Efectivo Descontados.

Dado que la mayoría de los estudios de valoración de empresas colombianas se encargan a grandes compañías de Banca de Inversión, se propone extender el conocimiento de este tema, a los pequeños y medianos empresarios que demandan nuevos conocimientos financieros y buscan permanentemente hacer crecer a sus empresas.

\section{Presentación del problema}

Dos de las grandes inquietudes para cualquier propietario, socio, accionista o inversionista de una empresa, independientemente de su tamaño, son las relacionadas con el valor de la misma y la forma de determinarlo. Estos interrogantes son más fáciles de resolver por grandes organizaciones que para las PyME$^{1}$, debido a las facilidades que tienen las primeras, para estructurar, revelar y analizar tanto la información financiera precisa y completa, como para la consecución de recursos económicos y humanos capacitados para este fin. Cayón y Sarmiento (2005) lo expresan así: "la valoración es un proceso costoso, que implica como mínimo un consumo de tiempo del área financiera y en muchas ocasiones supone la contratación de personas o compañías especializadas en realizar este tipo de trabajos" (p. 5). Dichas compañías se denominan Bancas de Inversión y normalmente facturan un porcentaje del valor de la negociación.

Si bien existen fuentes de información secundaria que abordan la valoración de empresas como se indica en la Tabla 1, ellas son difíciles de comprender o no le aportan clara y específicamente a los administradores de una PYME lo que deben hacer, al momento de determinar su valor y de una manera sistemática, ya que como lo expresan Saavedra (2011) y Sequeda (2014) es un tema de alta complejidad, principalmente por las técnicas que se utilizan. Y lo confirma Vargas (2015) cuando menciona que "el pequeño empresario tiene unas necesidades particulares de información que el sistema tradicional muchas veces no le satisface, por su lenguaje técnico y en ocasiones confuso con el que se le presenta" (p. 115) refiriéndose a que se hace necesario abordarlo de una manera más comprensible, dada la falta de conocimiento para llevar a cabo este proceso, siendo éste el objetivo del presente artículo. 
Tabla 1.

Algunos autores que abordan el tema de valoración de empresas

\begin{tabular}{|c|c|c|c|c|c|c|c|}
\hline & $\begin{array}{l}\text { Valoración de } \\
\text { empresas }\end{array}$ & $\begin{array}{c}\text { Métodos de } \\
\text { valoración de } \\
\text { empresas }\end{array}$ & $\begin{array}{l}\text { Ventajas y desventajas } \\
\text { de los métodos de } \\
\text { valoración }\end{array}$ & $\begin{array}{c}\text { Método de Flujos } \\
\text { de Caja } \\
\text { Descontados }\end{array}$ & $\begin{array}{l}\text { PYMEs en } \\
\text { Colombia }\end{array}$ & $\begin{array}{l}\text { Modelo para } \\
\text { valorar PYMES }\end{array}$ & $\begin{array}{c}\text { Aplicación de la } \\
\text { metodología a PYMEs } \\
\text { colombianas }\end{array}$ \\
\hline Rodríguez, M. (2000) & $x$ & $x$ & & & & & \\
\hline Serrano, J. (2000) & & $x$ & & $\mathrm{x}$ & & & \\
\hline García, O. L. (2003) & $x$ & $x$ & & $x$ & & & \\
\hline Vélez, I. (2004) & $x$ & $x$ & $x$ & $\mathrm{x}$ & & & \\
\hline Sarmiento, J. y Cayon, E. (2005) & $x$ & $x$ & & $\mathrm{x}$ & & & \\
\hline $\begin{array}{c}\text { Álvarez, R., García, K. y Borraez, } \\
\text { A. (2006) }\end{array}$ & $x$ & $x$ & & $x$ & & & \\
\hline Vélez, I. (2006) & & & & $x$ & & & \\
\hline Correa, J. y Jaramillo, F. (2007) & $x$ & $x$ & & & $x$ & & \\
\hline Espinosa, J. (2008) & $x$ & $x$ & & $x$ & & & \\
\hline Muñoz, C. y Pérez, A. (2008) & $x$ & & & $\mathrm{x}$ & & & \\
\hline $\begin{array}{l}\text { Arias, L., Portilla, L. y Fernández, } \\
\text { S. (2008) }\end{array}$ & $\mathrm{x}$ & & & $\mathrm{x}$ & & & \\
\hline García, O. L. (2009) & $x$ & & & $\mathrm{x}$ & & & \\
\hline Vidarte, J. (2009) & $x$ & $x$ & $\mathrm{x}$ & $x$ & & & \\
\hline $\begin{array}{l}\text { Castaño, J., Arias, L. y Portilla, L. } \\
\text { (2011) }\end{array}$ & $\mathrm{x}$ & & & & $\mathrm{x}$ & & \\
\hline Parra, A. (2013) & $x$ & $x$ & & $\mathrm{x}$ & & & \\
\hline Vargas, C. (2015) & $\mathrm{x}$ & & & & $\mathrm{x}$ & & \\
\hline
\end{tabular}

Fuente: Elaboración propia a partir de bibliografía consultada en Rodríguez, 2000; Serrano, 2000; García, 2003; Vélez, 2004; Sarmiento y Cayón, 2005; Álvarez, García y Borraez, 2006; Vélez, 2006; Correa y Jaramillo, 2007; Espinosa, 2008; Muñoz y Pérez, 2008; Arias, Portilla y Fernández, 2008; García, 2009; Vidarte, 2009; Castaño, Arias y Portilla, 2011; Parra, 2013 y Vargas, 2015.

\section{Justificación de la investigación}

La valoración de empresas y la gestión financiera dentro de las organizaciones son aspectos relevantes que abordan y sobre el cual comentan diferentes autores como Tascón, 2002; AECA, 2005; Correa y Jaramillo, 2007 y Saavedra, 2011.

Block y Hirt (2008) manifiestan que el valor de una empresa pequeña adquiere relevancia cuando se pone a la venta, o cuando forma parte de un arreglo de separación de bienes, o se requiere valorar para un proceso de sucesión cuando su propietario fallece, entre muchos otros.
El ejercicio de valoración de una empresa no solo se realiza con el fin de venderla o negociar parte de ella. Otro motivo importante que tiene que ver con esta labor, tiene que ver con "el deseo de implementar modelos de medición de creación de valor como parte del fomento de la cultura de la Gerencia del Valor" (García, 2003, p. 225) y por tal razón se hace necesario valorar el conjunto de la empresa y la gestión realizada. Es así como las Pymes se han profesionalizado al incorporar el concepto de creación de valor en su gestión, para determinar en qué medida las decisiones empresariales que toman contribuyen a la consecución de sus objetivos financieros (Tascón, 2002; AECA, 2005). 
De acuerdo a Tascón (2002), Gamboa (2003), García (2009), Jaramillo (2010) y Gómez (2014), el objetivo básico financiero de la gestión gerencial de cualquier organización, independiente de su tamaño, no es la maximización de utilidades o su rentabilidad, sino la maximización, en el transcurso del tiempo, del valor de sus acciones para sus asociados, accionistas, socios o gestores (Gitman y Zutter, 2012; Espinosa, 2008), en armonía con los objetivos asociados a los stakeholders de la organización (clientes, proveedores, accionistas, empleados, el Estado y la comunidad en general). Por lo tanto, se debe tener cuidado al examinar las finanzas incluso más de cerca que en compañías más grandes (Filion, Cisneros y Mejía-Morelos, 2011), porque la gestión que se realice en mercadeo, producción, talento humano e informática, termina repercutiendo sobre el área financiera (Alzate, 2013) y saberla administrar adecuadamente incrementa su productividad. "Para ello es necesario conocer los cambios en el valor de la empresa $y$, por tanto, es preciso saber cómo valorarla" (Milla y Martínez, s.f., p. 5).

\section{Marco teórico}

En la Figura 2, se presenta la secuencia de pasos que se deben seguir para obtener el valor financiero de una empresa, utilizando la metodología de Flujos de Efectivo Descontados, que de acuerdo a Fernández (2002), Labatut (2006), Rojo (2007), Vidarte (2009), Quemada (2013), Revello (2014) y Sequeda (2014), es el más utilizado, pues hace depender el valor de la empresa conforme a su capacidad futura para generar ingresos (flujos) para sus propietarios, además de su rigor metodológico, para no caer en criterios subjetivos sin ningún fundamento, como lo menciona Fernández (2002):

Al comienzo de una consulta de valoración que me encargó una empresa familiar, que estaba en venta, uno de los hermanos me dijo que él estimaba un valor de las acciones de unos 1.500 millones de pesetas. Al pregun- tarle de dónde procedía el valor, me respondió: Somos 3 hermanos accionistas y quiero que saquemos unos 500 millones cada uno (p. 23).

Se comenzará por describir cuál es el papel de la gestión financiera en el contexto de la Gestión de las Organizaciones y cómo se relaciona con el concepto de Valoración de Empresas y las metodologías que utiliza, para así aplicar estos conceptos en las PyMEs colombianas con base en la revisión de la literatura existente proveniente de diversos autores.

\section{Importancia de la gestión financiera dentro del contexto de la gestión de organizaciones y las Pymes.}

La gestión financiera, como área de la administración, se ocupa de lo concerniente a la creación de valor de las organizaciones y de las decisiones monetarias a corto (operativas), mediano y largo plazo (de capital) que toman las mismas y el gerente o gestor deberá rendir cuentas por los resultados que obtenga al gestionar dicho dinero.

Si bien las decisiones financieras a largo plazo determinan la capacidad de la empresa para incrementar al máximo la riqueza de los accionistas, ésta se puede ver comprometida, si los gerentes financieros fracasan al no tomar decisiones efectivas de corto plazo (Gitman y Zutter, 2012), para cumplir con los objetivos de la organización: crecer, permanecer en el tiempo y generar flujos de efectivo (García, 2009) de una manera sostenible en el futuro, para que tengan relación directa con la percepción de valor que el cliente otorga a sus productos (Camargo, 2006), como se aprecia en la Figura 1. "En principio esta misión será compartida por gestores financieros de grandes, medianas y pequeñas compañías; aunque como es lógico, encontraremos diferencias en el modo de calibrar el valor de la propia empresa" (Cantalapiedra, 2000, p. 36). 
Figura 1. Secuencia de la generación de valor

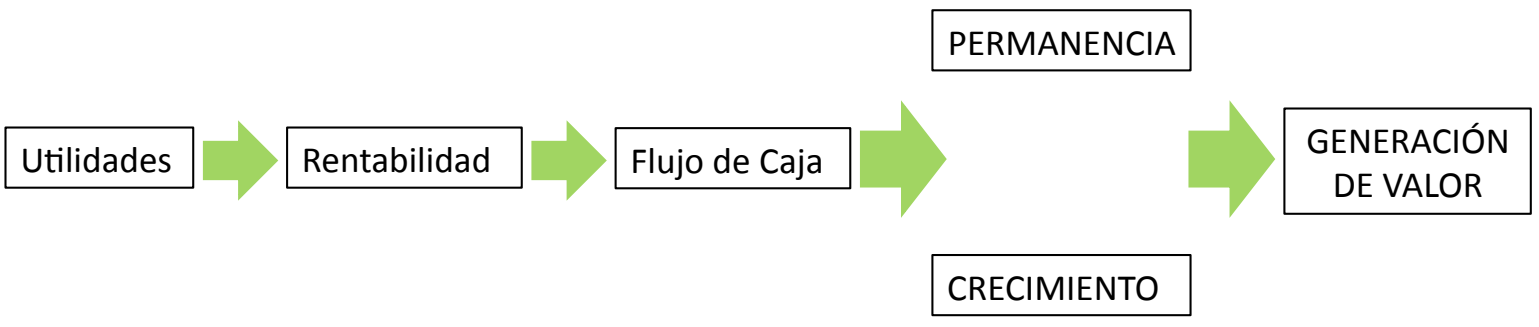

Fuente: García (2009).

Así, las decisiones de inversión, financiación y políticas de dividendos (distribución de utilidades), deben agregar a la empresa, tanto valor como sea posible (Dumrauf, 2013) para no afectar el crecimiento y la sostenibilidad de la organización a corto y largo plazo. Pero son las actividades de inversión y operación las que, cuando se produce un bien o un servicio, para después venderlo, crean valor y parte de este, es el que se utilizará para retribuir a los stakeholders (Cañibano y García, 2014).

Cuando las Pymes descuidan su administración, pierden el enfoque y aunque su producto o servicio sea de alta demanda, vigente o interesante, no logran mantenerse y fracasan. Teniendo en cuenta que la finalidad de todas las empresas es vender sus productos o servicios, es importante contar con una buena administración para lograrlo. La cultura empresarial, basada en el aprendizaje y la experiencia propia y de otras empresas en administración financiera, servirá para obtener mayor control de la organización.

En las Pymes, la función financiera, se enfoca hacia la contabilidad, costos, tesorería o presupuestos, con poca o nula planeación en estas áreas, ya que solo se planea a corto plazo y se encarga generalmente de dicha responsabilidad a una sola persona, quien típicamente arroja resultados ineficientes dados los pocos recursos (financieros y de tiempo) asignados para esta labor (Anzola, 2010). Esto ocurre en la etapa inicial de transformación de la Pyme, donde se cambia de una sola persona, a formar personal y estructurar un departamento financiero, propio o tercerizado, donde se desarrollen otras funciones de finanzas corporativas necesarias para el crecimiento de la empresa. Es en este punto, donde el gerente financiero se constituye en una persona importante para la mayoría de las empresas (Alzate, 2013). Independientemente del nombre atribuido, la función financiera va mucho más allá de una consecución de recursos (Jaramillo, 2010).

\section{Caracterización de las Pymes colombianas}

En Colombia, de acuerdo a la Ley 905 de 2004 en su artículo $2^{\circ}$ y desde el punto de vista cuantitativo, se entiende por empresa "toda unidad de explotación económica, realizada por persona natural o jurídica, en actividades empresariales, agropecuarias, industriales, comerciales, o de servicios, rural o urbana", que responda a unos parámetros determinados en cuanto a número de trabajadores y cantidad de activos totales (ver Tabla 2).

Tabla 2.

Clasificación de las empresas en Colombia de acuerdo a su tamaño

\begin{tabular}{|c|c|c|}
\hline Denominación & Planta de personal & Activos totales \\
\hline Microempresa & $\begin{array}{c}\text { No superior a 10 } \\
\text { trabajadores }\end{array}$ & $\begin{array}{c}\text { Inferior a 500 } \\
\text { SMMLV }\end{array}$ \\
Pequeña empresa & $\begin{array}{c}\text { Entre 11 a 50 } \\
\text { trabajadores }\end{array}$ & $\begin{array}{c}\text { Entre 501 y } \\
\text { 5.000 SMMLV }\end{array}$ \\
& $\begin{array}{c}\text { Entre 51 a 200 } \\
\text { trabajadores }\end{array}$ & $\begin{array}{c}\text { Entre 5.001 } \\
\text { Mediana empresa } 30.000\end{array}$ \\
& SMMLV \\
\hline
\end{tabular}

Fuente: Elaborado de acuerdo a la clasificación que hace de las empresas, la Ley 905 de 2004. 
Y en palabras de Vargas (2015):

Cabe resaltar que en Colombia no se considera otro factor determinante en la categorización de las empresas, y es el criterio correspondiente al nivel de ingresos, el cual es usado en varios países y por los medios especializados a nivel internacional, para ponderar y realizar ranking de las empresas en el contexto empresarial (p. 114).

De acuerdo a Camargo (2006), Puentes (2013) y al documento CONPES (Consejo Nacional de Política Económica y Social) 3484/07, algunas de las características más relevantes de las Pymes colombianas, desde el punto de vista financiero, son:

- Por su tamaño, no forman parte del mercado de capitales y poseen utilidades más bajas de lo que serían, si tuvieran acciones negociadas en la bolsa, debido a que "los propietarios de una gran cantidad de negocios pequeños mezclan los gastos personales con los gastos del negocio, para minimizar los impuestos" (Block y Hirt, 2008, p. 308).

- La estructura de financiación está basada en las necesidades del día a día.

- No tienen una gestión financiera definida y esta no responde a un enfoque estratégico específico, motivo de su limitado acceso al sector financiero.

- La contabilidad no se utiliza para tomar decisiones, ni refleja la situación real, económica y financiera de la empresa.

- Es generalizado el empleo de metodologías de costeo inadecuadas.

Beltrán, Torres, Camargo y Bello (2004) y al documento CONPES 3484 de 2007, aseguran que las micro, pequeñas y medianas empresas, tienen ventajas al ser actores estratégicos del desarrollo de la economía de un país, mejorando su posición competitiva y contribuyendo a reducir las brechas sociales. De otro lado, en el Informe Semanal de Asobancaria del 20 de junio de 2017, la misma entidad confirma que "en Colombia, el 99,5\% de las unidades de explotación económicas son MIPYMES, lo que las convierte en el principal cimiento de la actividad productiva nacional" (p. 1). Además, el documento expresa que estas "aglomeran alrededor del $67 \%$ del empleo y cerca del $38 \%$ del $P I B$ " (p. 2) lo que redunda en la mayor fuerza productiva del país.

\section{Valoración financiera de empresas}

El concepto de valoración financiera de empresas se asocia con el proceso para determinar un rango de valores objetivo que contempla el precio de negociación total o parcial para una empresa en marcha, con el propósito de que los propietarios o interesados utilicen esa información al momento de negociar o tomar decisiones (AECA, 2005; Espinosa, 2008; Aguiar, 2014; Fitó, 2015). "La razón de ser de la valoración, es la inexistencia de un mercado de empresas capaz de facilitar un valor por consenso entre los agentes económicos, tal como ocurre en el caso de las sociedades que cotizan en las Bolsas de Valores" (Aguiar, 2014, p. 167).

\section{Metodologías de valoración financiera de empresas}

De acuerdo con González y Medina (2003), Labatut (2005), Espinosa (2008), Vidarte (2009) y Tapia (2013) existen varios métodos para determinar el valor de una empresa, los cuales se pueden clasificar en 3 grandes grupos: 1. Los métodos basados en el Estado de la Situación Financiera, también denominados estáticos o contables, que incluyen el valor en libros, en valor en libros ajustado, el valor de reposición y el valor de liquidación. 2. los métodos basados en el Estado de Resultados, conocidos también como métodos comparativos, de mercado o por múltiplos, entre los cuales se encuentran el PER, indicador de ventas, EBIT y EBITDA, y 3. los métodos basados en Flujos 
de Efectivo, también conocidos como dinámicos o de retorno sobre la inversión, los cuales incluyen el Flujo de Efectivo Libre, el Flujo de Efectivo para el Accionista y el Flujo de Efectivo Operativo.

Las variables claves para elegir un método de valoración a aplicar son:

- el tamaño y sector al que pertenece la empresa,

- si la empresa cotiza en Bolsa de Valores o no,

- la información disponible y

- el objetivo que se quiere alcanzar con la valoración (Aguiar, 2014).

Hay que resaltar que las metodologías para valorar PyMES, son independientes al tamaño de estas, porque los principios utilizados para valorar las grandes empresas se aplican también a las pequeñas y medianas (FEE, 2001; AECA, 2004; Gómez, 2005; Rojo, 2007; Block y Hirt, 2008).

Haciendo referencia a los métodos basados en los valores contables, Fernández (2002) considera que "el problema fundamental de estos métodos es que unos se basan únicamente en el balance y otros en la cuenta de resultados, pero ninguno tiene en cuenta nada más que datos históricos" (p. 48), no las perspectivas futuras, ni consideran el factor tiempo del dinero, entre otras desventajas. Correa y Jaramillo (2007) agregan que son estáticas, sencillas y fáciles de aplicar, pero difíciles de justificar.

Es por ello que surge una metodología dinámica o basada en el descuento de flujos, en la que el valor de la empresa depende de su capacidad futura para generar ingresos, trabaja con datos financieros y son fáciles de justificar (Correa y Jaramillo, 2007); se define como la suma de los flujos económicos futuros esperados, descontados a una tasa que representa el costo del dinero y el riesgo de dichos flujos
(Espinosa, 2008). De igual forma, la Asociación Española de Contabilidad y Administración de Empresas - AECA (2004) sostiene que "el método de valoración de empresas que se basa en la actualización de los cash flows de la empresa es, a nuestro juicio, el que mejor se adapta a cualquier escenario de valoración, siempre que se trate de una empresa en funcionamiento" (p. 25). Y lo confirman González y Medina (2003) cuando expresan que es uno de los más adecuados para conocer el valor económico de una empresa.

\section{Metodología basada en Flujos de Efectivo Libre Descontados.}

Ha sido costumbre considerar como los estados financieros principales al Estado de la Situación Financiera y al Estado de Resultados, pero además agregan, los Flujos de Efectivo o Cash Flow (Decreto 2649 de 1993 en su artículo 22) en sus 3 variantes: El Flujo de Efectivo Libre (FEL), el Flujo de Efectivo de Capital (FEC) y el Flujo de Efectivo para el accionista (FEA) que reflejan las entradas y salidas de efectivo generado o demandado por la empresa como resultado de cambios producidos en diferentes rubros del Estado de la Situación Financiera y el Estado de Resultados, a través de 3 actividades: operación, inversión y financiación (Jaramillo, 2010; Alzate, 2013) el cual es necesario para su normal funcionamiento, ya que permite la supervivencia o quiebra de una empresa (Saavedra, 2011). Este será la base para calcular el valor de la empresa.

Con base en la información que arroja el Estado de la Situación Financiera y el Estado de Resultados históricos, es necesario construir y proyectar los Flujos de Efectivo durante algunos años (García, 2009), realizando los presupuestos necesarios, así:

Ingresos por ventas

( - ) Costo de ventas

UTILIDAD BRUTA 
( - ) Gastos de administración y ventas

UTILIDAD OPERACIONAL (EBITDA)

( - ) Intereses e impuestos

UTILIDAD NETA

(+) Depreciaciones y amortizaciones de activos diferidos

$(+)$ Intereses

\section{FLUJO DE EFECTIVO BRUTO}

( - ) Aumento del capital de trabajo neto operativo

( - ) Aumento de activos fijos para reposición

\section{FLUJO DE EFECTIVO LIBRE}

( - ) Servicio a la deuda

\section{FLUJO DE EFECTIVO DE LOS PROPIETARIOS}

Para calcular el valor de la empresa, es más recomendable utilizar el Flujo de Efectivo Libre Descontado (Santandreu y Torres, 2012) aunque independientemente de las variantes que se utilizan, debe dar como resultado el mismo valor (Federation des Experts Comptables Europeens, FEE, 2001). Se le llama Flujo de Efectivo Libre Descontado, porque trae a valor presente, el Flujo de Efectivo Libre que generará la empresa, durante los años de su vida futura y se podrá repartir a los propietarios y a los acreedores financieros.

\section{Elementos que componen la metodología basada en Flujos de Efectivo Libres Descontados:}

Tasa de descuento: Es la tasa que trae al presente, todos los flujos de efectivo proyectados, acorde con el riesgo asociado de ellos. "Cuanto mayor es el riesgo inherente al negocio, más pequeño es el valor actual del mismo" (Fitó, 2015, p. 34).

Esta tasa se denomina Costo Promedio Ponderado de Capital (CPPC) de la empresa, o WACC (Weighted Average Cost of Capital) en inglés, que constituye la base para la toma de decisiones de inversión en las empresas. "Cuando se habla de costo de capital, se hace referencia a los intereses que se deben pagar o retribuir a todos los que están financiando a la compañía" (Sequeda, 2014, p. 139), en lugar de que ellos (acreedores o propietarios) inviertan sus fondos en otra empresa con riesgo equivalente y viéndose afectada por factores económicos del entorno y la estrategia corporativa, siendo estas, tasas nominales (Vélez, 2006). Se calcula ponderando el costo de todas las fuentes de financiamiento que componen el pasivo de la empresa (estructura financiera de la empresa), es decir, recursos externos o deuda y recursos propios o patrimonio, "excluyendo algunos pasivos de corto plazo que no tienen costo, como proveedores, salarios por pagar, impuestos por pagar, etc." (Arias, Portilla y Fernández, 2008, p. 271) siempre y cuando éstos se paguen en los plazos convenidos y no generen mora alguna. Aconsejado por Cruz (2012) cuando indica no tener en cuenta la deuda a corto plazo, ya que esta se pagará en un tiempo igual o inferior a un año. La proporción de cada una de las fuentes de financiación (D o E) va a depender del costo de las mismas.

El CPPC se calcula por la fórmula 1 (Aguiar, 2014; Armendáriz, 2012; Revello, 2014).

$$
C P P C=\frac{(K e) *(E)}{D+E}+\frac{(\mathrm{Kd}) *(1-\mathrm{t}) *(\mathrm{D})}{\mathrm{D}+\mathrm{E}}
$$

Donde:

$$
\begin{aligned}
& \text { CPPC = Costo Promedio Ponderado } \\
& \text { de Capital (WACC) después de } \\
& \text { impuestos. } \\
& \mathrm{Ke}=\text { Costo del patrimonio o de los recursos } \\
& \text { propios. } \\
& \mathrm{E}=\text { Valor de mercado de los recursos } \\
& \text { propios (patrimonio o Equity). } \\
& \mathrm{E} /(\mathrm{D}+\mathrm{E})=\text { Peso relativo de los recursos } \\
& \text { propios }
\end{aligned}
$$

$\mathrm{Kd}=$ Costo de la deuda 
$\mathrm{D}=$ Valor de mercado de la deuda a largo plazo.

$\mathrm{D} /(\mathrm{D}+\mathrm{E})=$ Peso relativo de la deuda

$\mathrm{t}=$ Tasa de impuesto de renta

De acuerdo a Block y Hirt (2008), algo importante a tener en cuenta es que los costos que se considerarán son aquellos relacionados con los nuevos fondos que se usarán para el financiamiento futuro, en lugar de los costos históricos.

El cálculo de cada variable significa considerar los siguientes aspectos:

Costo del patrimonio (ke): Es la tasa de oportunidad requerida por los inversionistas para hacer una inversión sin riesgo en una empresa, en lugar de invertir sus fondos en otro negocio con riesgo equivalente.

Una técnica utilizada para el cálculo del costo de los recursos propios, se basa en el Capital Asset Pricing Model - CAPM (Parra, 2013); modelo desarrollado por William Sharpe en 1964 y se puede calcular con la fórmula 2 (Armendáriz, 2012; Parra, 2013).

$$
K e=R f+\beta(R m-R f)
$$

Donde:

$$
\begin{aligned}
& \mathrm{Ke}=\text { Costo del patrimonio o de los recursos } \\
& \quad \text { propios } \\
& \mathrm{Rf}=\text { Tasa libre de riesgo } \\
& \beta=\text { Beta de la empresa en relación con el } \\
& \text { mercado. }
\end{aligned}
$$

$(\mathrm{Rm}-\mathrm{Rf})=$ Prima de riesgo de mercado.

El asunto más delicado para la estimación del modelo CAPM, y por consiguiente del CPPC, en economías emergentes donde el desarrollo del mercado de capitales es aún escaso, es el relacionado con los riesgos adicionales y con las pocas fuentes de información cuando las empresas no cotizan en bolsa y que motivan algunos ajustes al modelo original. Con el fin de acercar los resultados al entorno colombiano como un mercado emergente, López y Luna (2001) y Sosa (2014) aconsejan sumarle a la anterior ecuación, una prima de riesgo del país (Rp), variable propia de la economía nacional para reflejar factores adicionales de incertidumbre sobre todo para un inversionista extranjero, convirtiendo la fórmula 2 en una nueva (fórmula 3).

$$
K e=R f+R p+\beta(R m-R f)
$$

De acuerdo a lo anterior, el modelo CAPM parte de la identificación de una relación entre el riesgo y el rendimiento, en la cual el rendimiento esperado de una acción es igual a la suma de una tasa libre de riesgo de una economía (Rf), una tasa de riesgo país ( $\mathrm{Rp}$ ) y una prima por exponerse al riesgo del mercado de acciones, en lugar de invertir en un titulo libre de riesgo. Esta última prima esta compuesta por una prima de mercado (Rm - Rf) y un coeficiente beta $(\beta)$.

De acuerdo a lo expresado por Trujillo y Martínez (2016), el CAPM tiene en cuenta no solo, el costo de oportunidad de invertir los recursos de los inversionistas en la empresa a cambio de una deuda con terceros, sino también los riesgos del mercado y los betas donde opera la empresa.

Los componentes del Costo del patrimonio son:

Tasa libre de riesgo (Rf): Es una tasa que representa la rentabilidad que un inversionista percibe por una inversión con riesgo nulo o minimo de incumplimiento.

Generalmente se utiliza como referencia el rendimiento anual que ofrecen los bonos que emite el Departamento del Tesoro de Estados Unidos a largo plazo (T-Bonds, bonos del tesoro o Treasury bonds) a 10, 20 o 30 años, ya 
que se consideran libres de riesgo, con garantía del Estado y suficiente liquidez. En Colombia esta tasa se puede asociar a los títulos de deuda pública emitidos por el gobierno, denominados TES (Títulos de tesorería), administrados por el Banco de la República que tienen plazos a 1, 5 o 10 años (Gómez, 2005; Jaramillo, 2010) y se calcula como el rendimiento promedio anual de los TES con vencimiento a 10 años (hasta el periodo actual de estudio).

De acuerdo a lo expresado por Martínez, Ledesma y Russo (2013), cuando se analiza una inversión en un país emergente, no se puede considerar la tasa libre de riesgo de los bonos norteamericanos sino la tasa que se tiene en dicho país emergente, puesto que lo que se desea conocer es el riesgo de operar en dicho país.

Aceptando que los inversionistas ponen sus recursos a un largo periodo de tiempo, lo correspondiente es utilizar como tasa libre de riesgo, una tasa de largo plazo (Rojo, 2007). Milla y Martínez (s.f.), y Vargas (2011) aconsejan utilizar los bonos del Estado a 10 años, ya que "dicho periodo de tiempo es menos sensible a la inflación, se aproxima mejor a la duración del índice del mercado y es más congruente con el horizonte temporal que se utiliza en la proyección de los FCL de una compañia”.

Tasa de riesgo país ( $R p)$ : Cualquier empresa en un país emergente está expuesta a cambios frecuentes en las políticas económicas, la situación social, la legislación laboral y tributaria del propio país, y otros aspectos (Trujillo y Martínez, 2016), esto puede conllevar a variaciones inesperadas en el entorno operacional del negocio, por lo cual el inversionista exigiría un rendimiento mayor, al exponerse a un riesgo adicional de operar en Colombia.

Este índice es calculado por firmas internacionales de calificación de riesgo como J.P. Morgan Chase, que mide el riesgo de impago (default) de las obligaciones financieras de un país y se sustenta con base en el índice EMBI (Emerging Markets Bonds Index o Indicador de bonos de mercados emergentes), de acuerdo al comportamiento de la deuda externa que emite cada país, y se calcula como la diferencia (spreads) entre la tasa de rendimiento promedio que pagan los bonos del tesoro americanos (T-bonds) en dólares y la tasa de rendimiento que pagan los bonos de Colombia (TES) en dólares, expresados en puntos básicos $(100 \mathrm{pb}=$ $1 \%)$. Estos puntos adicionales reflejan el mayor riesgo que implicaría invertir en Colombia para un inversionista. Mientras menos certeza exista que un país cumplirá con sus obligaciones, mas alto será su EMBI y viceversa.

Prima de riesgo del mercado $(R m-R f)$ : Está calculada como la diferencia entre el promedio aritmético de la rentabilidad histórica ofrecida por el mercado accionario de la economía colombiana (índice bursátil que refleja el comportamiento de las acciones) a largo plazo y el promedio aritmético de la rentabilidad histórica de los bonos de tesorería emitidos por el gobierno cuyo riesgo tiende a cero (tasa libre de riesgo), también a largo plazo. Dicha prima de riesgo mide lo que los inversionistas exigen como rentabilidad adicional por tener que asumir un riesgo, al optar por una inversión distinta a aquella que reporta una rentabilidad asegura$\mathrm{da}$, a iguales periodos de tiempo.

La rentabilidad del mercado se mide con un índice asociado a un conjunto de acciones de varias industrias que muestra lo que demandan los inversionistas del mercado en su conjunto. En el caso de Estados Unidos, los índices que se utilizan son el Standard \& Poors 500 o el NYSE Composite Index. En Colombia su equivalente es el Índice General de la Bolsa de Valores de Colombia - IGBC (Cruz, 2012), hoy en día COLCAP, comparando el índice de una fecha con el de una fecha anterior, lo cual indica que el mercado como un todo, tuvo una variación en los precios de las acciones mas líquidas de la BVC, de un tanto por ciento entre 2 fechas consecutivas. 
De acuerdo a Vélez (2006) hay que tener en cuenta que en mercados de países en desarrollo, el mercado accionario presenta a veces rendimientos negativos y si el rendimiento de los TES es mayor, da como resultado una prima de mercado negativa. A pesar de esto, se puede continuar utilizando el modelo CAPM con una variación: utilizando una prima de riesgo de un mercado desarrollado como la de Estados Unidos (S\&P 500) ajustada por la inflación y por la devaluación en Colombia.

Beta de la empresa ( $\beta$ ): Es un coeficiente de volatilidad del riesgo sistemático (no diversificable) del rendimiento que tiene una acción en respuesta a un cambio en el rendimiento del mercado, calculado sobre rendimientos históricos, en función de las diferencias de los riesgos operativos y financieros de la empresa, junto con el tipo de negocio en que opera. El riesgo sistemático, o no diversificable, deriva en que además del riesgo específico de una empresa (riesgo no sistemático o diversificable), existen factores externos que amenazan a todas las empresas (inflación, tasas de interés, eventos políticos, entre otros). De acuerdo a Gitman y Zutter (2012) la mayoría de los coeficientes betas están entre 0.5 y 2.0 .

Los factores que determinan el coeficiente beta son, entre otros, el tamaño de la compañía, el tipo de negocio que desarrolla y el grado de apalancamiento operativo y financiero; a mayor tasa de crecimiento de capital invertido, mayor riesgo y mayor apalancamiento, mayor $\beta$ y viceversa (Milla y Martínez, s.f.).

Al valorar una Pyme "el riesgo que soportan estas empresas es mayor que el resto de empresas como consecuencia de su menor tamaño, de sus problemas de liquidez, de su gestión y dificil acceso al mercado de capitales" (Labatut, 2006, p. 19).

Existen dos tipos de betas dependiendo de la cantidad de deuda que tenga la empresa: la beta desapalancada (unlevered) tiene en cuenta únicamente el riesgo operativo, sin considerar la deuda de la empresa y la beta apalancada (levered) incluye además el riesgo financiero, asociado al porcentaje de deuda que se utiliza en la estructura de capital (D/E). Al reflejar el efecto de la estructura financiera de la empresa, la beta apalancada siempre sera mayor que la beta desapalancada por el riesgo que produce el endeudamiento (Cruz, 2012).

Dado que en Colombia, no se cuenta con una fuente oficial que realice los cálculos de los beta sectoriales, por ser pequeño el mercado de valores donde cotizan pocas empresas, se puede recurrir a los betas de las empresas estadounidenses o de empresas comparables del mismo sector, que si cotizan en bolsa, desapalancadas (que solo toman en cuenta el riesgo operativo) y ajustarlas (apalancarlas) en función de la estructura financiera del negocio en particular, en el país emergente. De acuerdo a García (2003) y Sosa (2014), la fórmula para hallar la beta apalancada es:

$$
\beta_{\mathrm{L}}=\beta_{\mathrm{U}} *(1+(1-\mathrm{t}) *(\mathrm{D} / \mathrm{E}))
$$

Donde:

$$
\begin{aligned}
& \beta_{\mathrm{U}}=\text { Beta desapalancada } \\
& \mathrm{t}=\text { Tasa de impuesto de renta } \\
& \mathrm{D} / \mathrm{E}=\text { Estructura de capital de la empresa }
\end{aligned}
$$

Costo de la deuda (Kd): Es el costo medio de las diferentes obligaciones financieras que el mercado cobra a la empresa por los préstamos y créditos contraídos con terceros, que causen interés efectivo. Luego ese valor se pondera (valor porcentual) para la clase de deudas tanto a corto plazo (corrientes) como a largo plazo (no corrientes), sobre el total de la deuda, establecidos como intereses pagados a cada clase. Es importante conocer el costo de la deuda periodo a periodo (puede ser diferente por la variedad de plazos y costos de las diferentes fuentes de financiación), los intereses pagados y el costo combinado de cada periodo (Vélez, 2006). 
El costo de la deuda puede depender de varias variables: el sector en la que se desenvuelve la empresa, su tamaño, las tasas de interés vigentes, el riesgo financiero o de insolvencia de la empresa, los plazos de financiamiento, la calificación de riesgo, la desgravación fiscal de los intereses y el manejo eficiente en sus fuentes de financiación, entre otras (Mascareñas, 2000; García, 2003; Gómez, 2014).

"Ya que los intereses son deducibles de impuestos, se deben descontar de estos, lo que se traduce que el costo de la deuda sea $K d *(1-t)$ " (Arias, Portilla y Fernández, 2008, p. 272), haciendo de estos, una fuente de financiación económica.

La tasa de interés, costo de la deuda $\mathrm{Kd}$, se basa en una tasa variable de referencia para Colombia que es la DTF vigente, a la cual se le puede sumar, otra porción (spread bancarios) para reflejar la situación financiera propia de la empresa y el riesgo percibido por la banca local. La planeación financiera definida por la empresa debe indicar la manera cómo va a financiarse en el futuro (Vélez, 2006).

La tasa DTF (Depósito a Término Fijo) es la principal tasa de referencia en Colombia y resulta de computar las tasas de captación promedio ponderada semanales que pagan las entidades financieras a los CDT (Certificados de Depósito a Término) de 90 días. Es calculada por el Banco de la República con información proveniente de la Superintendencia Financiera de Colombia con periodicidad semanal de los 7 días previos para su vigencia.

De igual forma, si la deuda es contraída con bancos en el exterior, la tasa de referencia puede ser la LIBOR o la PRIME, dependiendo del país, más los spread correspondientes y es fundamental tener en cuenta la devaluación o revaluación del peso colombiano, con respecto a dicha moneda y también la inflación en ambos países.
Tasa de impuesto de renta: El impuesto de renta es determinado por el Estado y consiste en el tributo que paga una organización por las utilidades obtenidas en un periodo determinado el cual, generalmente, es un año.

Flujo de Efectivo Libre: El Flujo de Efectivo Libre (FEL) o Free Cash Flow (FCF) en inglés, es el flujo de dinero generado por las operaciones de la empresa que quedan disponibles para remunerar a sus proveedores de financiación (acreedores financieros o accionistas) "sin considerar la estructura de capital es decir, como si la empresa no tuviera deuda o se financiara solamente con capital propio" (Tapia, 2013, p. 81). "A los acreedores financieros se les atiende con el servicio de la deuda (capital e intereses) y a los accionistas con dividendos" (Zitzmann, 2009, p. 19). El concepto de efectivo se refiere también al dinero en otras cuentas, que sean susceptibles de volverse efectivo en cualquier momento.

De acuerdo a Fernández (2002), García (2003), Garzón y González (2008), Jaramillo (2010), Gitman y Zutter (2012), Sosa (2014) y Ortiz (2015), la forma de calcular el flujo de efectivo libre, de manera indirecta $y$ clasificada, es:

Utilidad Operacional Neta Después de Impuestos (UONDI / NOPAT)

(+) Depreciaciones

$(+)$ Amortizaciones

$(+/-)$ Cambios en el Capital Neto de Trabajo

(+ / -) Cambios en los Activos Fijos (CAPEX)

FLUJO DE EFECTIVO LIBRE (FCL)

La estimación de estos rubros se puede obtener a partir del Estado de Resultados, así: 
La depreciación y amortizaciones que aparecen en el Estado de Resultados, son deducciones que no representan una salida física de efectivo y por esto se pueden sumar a la utilidad. Las empresas usan el gasto de depreciación para asociar los gastos provenientes de activos fijos, con los ingresos que ellos mismos generan.

Los cambios en el capital neto de trabajo responden a las inversiones que debe efectuar la empresa para mantener el giro habitual del negocio, financiadas con deuda o capital propio, reducen o incrementan el saldo de efectivo (indirectamente). Se calculan como la diferencia entre los activos corrientes y los pasivos corrientes.

Los cambios en los activos fijos (CAPEX) corresponden a las inversiones en activos de larga duración o las realizadas en planta y equipo, ya sean nuevos o para su reemplazo, con el fin de mantener la capacidad productiva de la empresa, incrementando o reduciendo el saldo de efectivo. Pueden calcularse como el incremento neto en activos fijos del Estado de Situación Financiera más los gastos de amortización (depreciación) del periodo.

Valor Residual: Es el valor esperado que posee la empresa, generado por los flujos de efectivo futuros a perpetuidad (análisis hacia el futuro), tras el periodo finito del horizonte temporal estimado (de cinco a diez años), midiendo la generación de valor de la empresa más allá de su periodo finito, cuando esta se ha consolidado y sigue produciendo. Este debe considerarse como un solo periodo, con expectativas racionales y similares a las del último año o año cinco (Tapia, 2013). Por la experiencia de Vélez (2004), este valor es el que define si un proyecto es bueno o no. Al considerar que el primer periodo es infinito, durante el mismo se obtendrán unos flujos de efectivo que podrán ser crecientes en función de una tasa de crecimiento constante o del crecimiento del sector, aunque después de algunos años (treinta o cuarenta) las diferencias que existen entre el análisis de todos los años de la empresa y una perpetuidad, se reducen a valores insignificantes (Tapia, 2013).

"Es importante hacer notar que el valor residual puede llegar a representar, en algunos casos, más del $60 \%$ o el 70\% del valor de la empresa" (Rojo, 2007, p. 103). Koller, Goedhart y Wessels (2010) mencionan como ejemplo, la participación promedio de esta variable sobre el valor total de las compañías en 4 industrias, dado un pronóstico de 8 años, representando desde un $56 \%$ hasta un $125 \%$ del valor total de las empresas.

Valor Financiero Total de la empresa: El valor total de la empresa vendría determinado en el momento presente, por el valor actual (no neto) de los Flujos de Efectivo Libre futuros que ella es capaz de generar en un periodo de tiempo determinado, más el valor residual actualizado (no neto) de la empresa, de acuerdo a la tasa de descuento considerada (Narváez, 2009; Aguiar, 2014).

Posteriormente, mediante un análisis de sensibilidad se definen mínimo tres escenarios: pesimista, base y optimista, teniendo en cuenta las variables claves del Estado de Resultados y el Estado de Situación Financiera y de otro lado, parámetros de valoración como la tasa de descuento y la tasa de crecimiento a perpetuidad del valor residual (Revello, 2014) para determinar un rango de valores para la valoración financiera. Koller, Goedhart y Wessels (2010) recomiendan apuntar a un rango de valoración de más o menos un $15 \%$, similar al utilizado por muchos banqueros de inversión.

\section{Enfoque metodológico}

Para determinar el valor financiero de una PyME, se establecerá la construcción de una metodología de aplicación de los conocimientos, acorde con las condiciones de las pequeñas y medianas empresas colombianas, 
compuesta por una serie de pasos secuenciales (Bedoya, 2000; Fitó, 2015; Revello, 2014; Sequeda, 2014) que se describen en la Figura 2. Es un tipo de estudio descriptivo, porque se describe detalladamente cómo llevar a cabo un proceso de valoración para PyMES, independientemente del sector al que pertenezcan, mediante el método de Flujos de Efectivo Descontados y soportado en la revisión bibliográfica y documental de fuentes secundarias en la literatura de valoración de empresas.

El documento tiene un enfoque cualitativo dado que se proporcionará una metodología que sirva de base para que las empresas comprendan e identifiquen cómo obtener su valor financiero. Como complemento, se tendrá un enfoque cuantitativo, que se pretende orientar acerca de las variables financieras, tanto de la empresa, como del entorno, que se deben tener en cuenta para dicho proceso, a partir de los Estados Financieros históricos y proyectados.

\section{Resultados de la investigación}

"La valoración de una empresa es un proceso; nunca la simple aplicación de una fórmula matemática" (Milla y Martínez, s.f., p. 12) y como proceso, existen cuatro elementos básicos para la aplicación de la metodología basada en Flujos de Efectivo Descontados, que se deben tener en cuenta: el horizonte de planeación, la tasa de descuento, los flujos de efectivo libre y el valor de continuidad o residual, los cuales se explican conforme se desarrollan las etapas del proceso para valorar una empresa.

Con base en la fundamentación teórica existente de valoración de empresas y de acuer-

Figura 2. Etapas para estimar el valor total de una empresa.
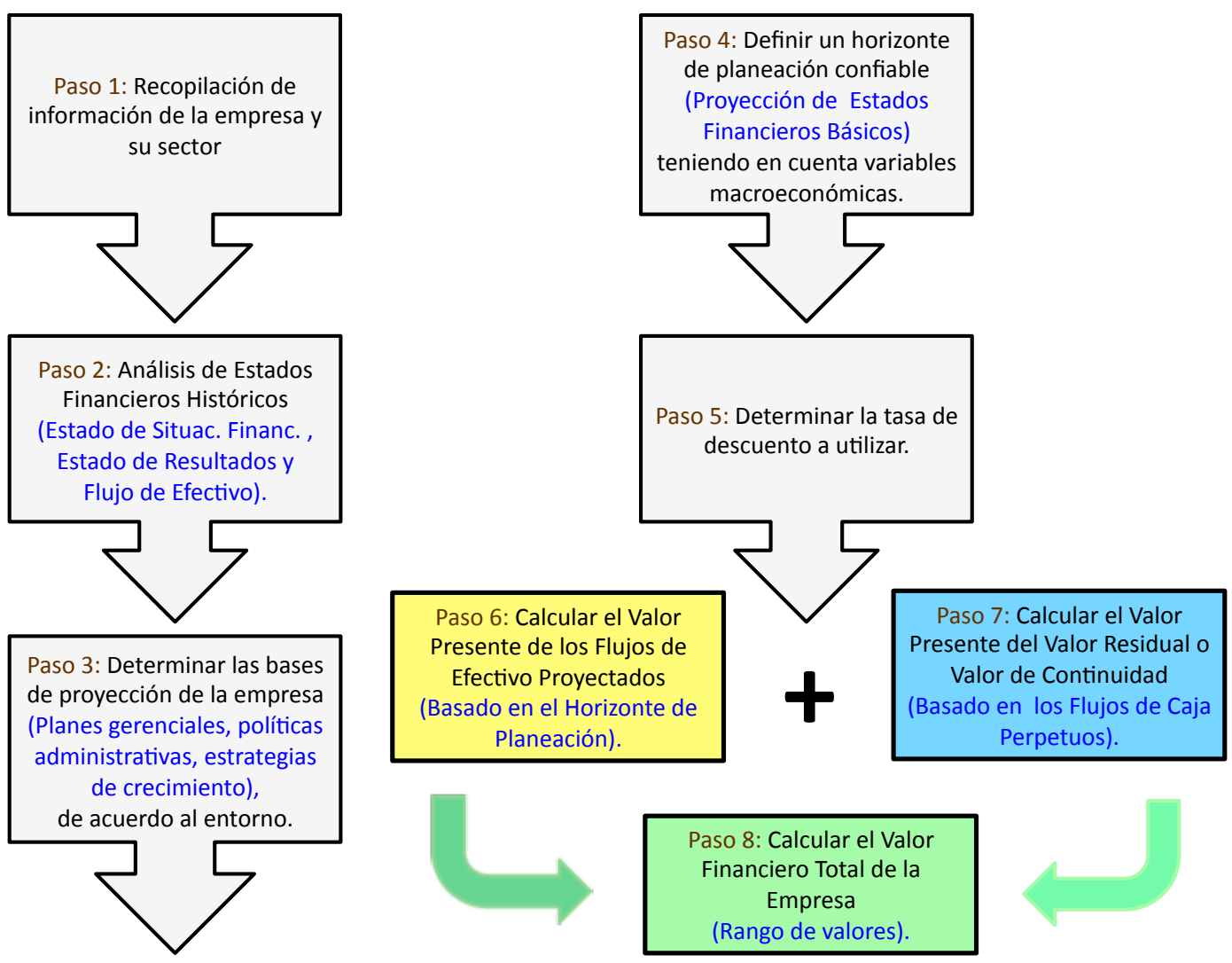

Fuente: Elaboración propia a partir de Bedoya (2000); Fitó (2015); Revello (2014) y Sequeda (2014). 
do con AECA (2005) y Gómez (2005), la valoración de una PYME se rige por los mismos fundamentos metodológicos en los que se basan las valoraciones de grandes empresas. Las etapas del proceso se representan en la Figura 2.

Paso 1: Recopilación de información amplia o completa de la empresa para hacer un análisis de la situación pasada, presente y una proyección de futuro, que pueda ser verificable, fiable y consistente (FEE, 2001).

Valorar la situación financiera de la empresa implica conocer:

- A su personal desde lo cognitivo y emocional,

- Su administración,

- Su forma de actuar y de resolver problemas,

- Su cultura organizacional,

- Su evolución histórica,

- Su estructura organizacional,

- Su tamaño,

- Sus líneas de producto,

- Su capacidad instalada,

- Su porcentaje de utilización de la misma,

- Las inversiones realizadas,

- La tecnología adecuada para satisfacer al mercado,

- Su entorno y la industria en la que se desenvuelve,

- La información específica del mercado, situación actual y potencial de crecimiento,

- Los proveedores, competencia y clientes,

- Su posición estratégica.

Información financiera inicial, suficiente y de calidad, en especial, estados financieros como el de Situación Financiera, el de Resultados y los Flujos de Efectivo, preferiblemente auditados, son importantes al provenir de la propia empresa, así como las notas generales y específicas a los mismos. Hay que tener en cuenta la distribución y representación de los activos; relación deuda sobre el patrimonio y la composición de ambos; evolución de la deuda bancaria y los gastos financieros; valor y crecimiento de las utilidades operacional y neta, incidencia de los ajustes por inflación, entre otros (Ortiz, 2015). La información relativa al pasado y al presente, tiene importancia en la medida que servirá como base para efectuar y evaluar el desempeño futuro, con más profundidad (Milla y Martínez, s.f.; FEE, 2001).

Paso 2: Análisis de datos históricos.

Normalmente se utilizan Estados de Situación Financiera y Estados de Resultados históricos, entre otros, de cuatro o cinco periodos consecutivos, con el objeto de determinar los Flujos de Efectivo históricos, evaluar el rendimiento económico y financiero de la empresa y determinar las razones reales de su éxito a la fecha.

Paso 3: Determinación de las bases de proyección, de acuerdo a las condiciones del entorno en que se desenvuelve la empresa.

Para la construcción del entorno, se requiere el planteamiento de algunos elementos de planeación financiera que aborden los aspectos económicos, políticos, sociales, culturales e industriales y las características internas de la empresa, porque ellos inciden sobre el comportamiento de la empresa en el futuro:

- Planes estratégicos y gerenciales

- Políticas contables y administrativas, de dividendos, económicas y gubernamentales, planes de inversión, de capitalización, endeudamiento y tecnológicos, entre otros. 
- Factores macroeconómicos estimados (inflación, tasa de cambio, devaluación, PIB, DTF, tasa de intervención del Banco Central, riesgo país, etc.), son un insumo importante para la proyección financiera.

En Colombia, el Banco de la República es una fuente de consulta para las proyecciones macroeconómicas anuales relacionadas con los indicadores y no van más allá de 5 años, ya que "ese sería el máximo rango de tiempo para el que podría proyectarse de manera detallada el flujo de efectivo libre" (García, 2003, p. 314).

Paso 4: Proyección de los estados financieros básicos con base en el horizonte de planeación (periodo de pronóstico).

Una vez analizadas las características internas de la empresa y los datos históricos de la misma, se efectuarán proyecciones financieras para cinco años como mínimo, de los estados financieros correspondientes al Estado de Situación Financiera, el Estado de Resultados y el Flujo de Efectivo, que permitan obtener los flujos esperados que puede originar la empresa en función del comportamiento histórico y la capacidad de crecimiento (Labatut, 2006) e integradas de tal manera, que los rubros de los estados financieros muestren el impacto que tienen sobre estos (Parra, 2013).

Se recomienda elaborar unos cuadros denominados presupuestos con el fin de que la proyección final de los estados financieros resulte más sencilla y fácil de entender. Algunos son: presupuesto de ventas, presupuesto de caja, presupuesto de gastos de administración, ventas $\mathrm{y}$ financieros, presupuesto de otros ingresos y otros egresos, planes de inversión, financiación y de amortización de deudas de largo plazo, presupuesto de producción (si la empresa es manufacturera), de consumo y compra de materias primas, mano de obra y costos indirectos de fabricacion (si la empresa es manufacturera), presupuesto de costos de mercancías vendidas (si la empresa es comercial).

El horizonte de planeación o periodo de pronóstico se refiere hasta qué momento futuro en el tiempo se considerarán las actividades de la empresa para lograr el resultado final anual y así proyectar los Estados Financieros. "Para la preparación del Flujo de Caja se parte de la base de que la empresa tiene una vida indefinida y continua" (González y Medina, 2003, p. 15), la cual está dividida en 2 etapas: Análisis del pasado y análisis hacia el futuro, como se muestra en la Figura 3.

Figura 3. Vida de la empresa dividida en 2 fases

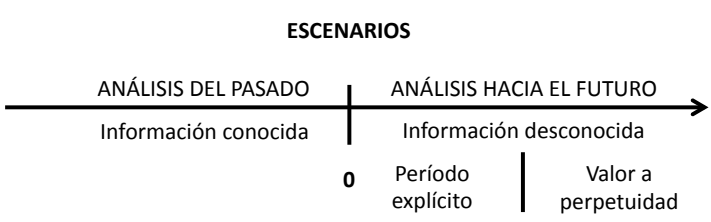

Fuente: Elaboración a partir de González y Medina (2003).

El análisis del pasado o información histórica (previo a la valoración) es un periodo de tiempo (entre cuatro y cinco años) donde la empresa tiene información conocida y exacta para la construcción de sus flujos de caja anuales. Mientras más amplio sea el periodo de tiempo, mayor grado de exactitud tendrá la valoración.

El análisis hacia el futuro (posterior a la valoración) es un periodo de tiempo en el cual la empresa no tiene información y deberá, con base en supuestos, estimar los resultados que se producirán por el desarrollo de sus actividades de acuerdo al desempeño histórico de la empresa. Según el desarrollo del mercado donde opera la empresa, se define el rango de tiempo a futuro. "Si la empresa se desarrolla en un mercado estable, el periodo del horizonte de planeación debe ser mayor, pero si la economía en la que se desarrolla tiene condiciones de inestabilidad, es preferible reducir el horizonte" (Tapia, 2013, p. 69). Esto significa que 
no existe un criterio único para determinar el rango de tiempo, porque depende tanto del escenario macroeconómico como del plan de desarrollo de la empresa (García, 2003). Aun así, la generalidad es utilizar un periodo de cinco a diez años.

Después del último año del período de pronóstico (periodo explícito), se estimará un Valor de Continuidad o Valor Residual, considerando que la empresa tiene una vida ilimitada, condición que se explica más adelante.

Paso 5: Cálculo de la tasa de descuento.

Una vez estimados los Flujos de Efectivo Libres futuros, el siguiente paso es calcular su valor actual, utilizando una tasa de descuento que se obtiene calculando cada una de las variables que la componen.

Paso 5.1. Costo de la deuda (Kd): El Banco de la República en su página web, publica los datos históricos semanales y mensuales de la tasa DTF y las diferentes entidades financieras (bancos) en sus páginas web, publican tablas con las proyecciones de los indicadores macroeconómicos, entre ellos, la tasa DTF a varios años.

Si por ejemplo, el crédito comercial cuesta $8 \%$, el costo de la deuda se convertirá, con un nivel de impuestos en Colombia del $33 \%$, en el $5,36 \%$.

$$
\begin{aligned}
& \mathrm{Kd}=\mathrm{Kd} *(1-\mathrm{t}) \\
& \mathrm{Kd}=8 \% *(1-0.33) \\
& \mathrm{Kd}=5,36 \%
\end{aligned}
$$

Paso 5.2. Tasa de impuesto de renta ( $t$ : : A la fecha, y de acuerdo al artículo 100 de la Ley 1819 de 2016, en Colombia esta tasa es del 33\%.

Paso 5.3. Costo del patrimonio (Ke): Para alimentar este modelo se deben ingresar datos de valores esperados de $\mathrm{Rf}, \mathrm{Rp}, \mathrm{Rm}$ y $\beta$ y para ello se requiere trabajar con series históricas de los mismos, suponiendo que estas determinarán los valores futuros.

Paso 5.3.1. Tasa libre de riesgo (Rf): La información histórica de los TES está disponible en la página de internet del Banco de la República, en la sección de estadísticas bajo el link Tasas de interés / TES y la información publicada está diaria, semanal, mensual para plazos a uno, cinco o diez años.

Paso 5.3.2. Tasa de riesgo país (Rp): Este indicador se puede obtener de sitios especializados de internet, de manera histórica y diaria, entre ellos el diario financiero electrónico ${ }^{2}$.

Paso 5.3.3. Prima de riesgo del mercado $(R m-R f)$ : La información histórica del COLCAP está disponible en la página web del Banco de la República, en la sección de estadísticas, bajo el link Mercado bursátil y está disponible diariamente.

Paso 5.3.4. Beta ( $\beta$ ) de la empresa: La cifra del beta sectorial, se puede consultar en la página ${ }^{3}$ de internet del profesor Aswath Damodaran quien es un experto mundial en valoración de empresas, y tiene una base de datos que presenta betas por industria y sectores para países emergentes. En Colombia, en la página de internet de la Superfinanciera se pueden encontrar los cálculos de los betas.

De acuerdo a lo descrito para el paso 5, y en función de cumplir la metodología práctica propuesta como objetivo de este artículo, la forma de determinar el costo del patrimonio, de acuerdo a la fórmula (3), será:

$$
\begin{aligned}
& \text { Si Rf }=5.50 \%, \mathrm{Rp}=1 \%, \mathrm{Rm}=10.81 \% \mathrm{y} \\
& \beta=0.84 \\
& K e=R f+R p+\beta(R m-R f)
\end{aligned}
$$




$$
\begin{aligned}
& C P P C=\frac{(K e) *(E)}{D+E}+\frac{(\mathrm{Kd}) *(1-\mathrm{t}) *(\mathrm{D})}{\mathrm{D}+\mathrm{E}} \\
& \mathrm{Ke}=5.50 \%+1.00 \%+0.84 *(10.81 \%-5.50 \%) \\
& \mathrm{Ke}=10.96 \%
\end{aligned}
$$

De igual forma, la manera de determinar la tasa de descuento, asumiendo que la estructura de capital de una empresa es 50\% - 50\% y que el costo de la deuda es de $5.36 \%$, según la fórmula (1), será:

$$
\begin{aligned}
& \mathrm{CPPC}=(10.96 \%) *(0.5)+(5.36 \%) *(0.5) \\
& \mathrm{CPPC}=5.48 \%+2.68 \% \\
& \mathrm{CPPC}=8.16 \%
\end{aligned}
$$

Paso 6: Cálculo del Valor Presente de los Flujos de Efectivo Libre:

$$
\begin{aligned}
& \text { Valor Presente de los } \\
& \text { Flujos de Efectivo Libres }=\Sigma \frac{\left(F E L_{t}\right)}{(1+C P C)^{t}}
\end{aligned}
$$

Una vez obtenido el Flujo de Efectivo Libre para cada uno de los periodos del pasado y que estos se proyectaran al futuro, se traerá a valor presente o valor actual para cada uno de los t periodos, tomando como base un plazo mínimo de 5 años (el mismo tiempo del horizonte de planeación) y “descontándoles una tasa que incorpore el riesgo inherente" (Fitó, 2015, p.25) que se denomina Costo Promedio Ponderado de Capital, mediante la ecuación (5):

Donde:

$$
\begin{gathered}
\text { Valor Presente de los } \\
\text { Flujos de Efectivo Libres }=\Sigma \frac{\left(F E L_{t}\right)}{(1+C P P C)^{t}} \\
\text { V.P.Flujos de Efectivo Libres }=\frac{(\$ 107.00)}{(1+0.0816)^{1}}+\frac{(\$ 124.70)}{(1+0.0816)^{2}}+ \\
\frac{(\$ 152.07)}{(1+0.0816)^{3}}+\frac{(\$ 200.43)}{(1+0.0816)^{4}}+\frac{(\$ 249.45)}{(1+0.0816)^{5}} \\
\text { V.P.Flujos de Efectivo Libres } \\
\text { \$98.93+\$106.59 }+\$ 120.18+\$ 146.45+\$ 168.52 \\
\text { V.P.Flujos de Efectivo Libres }=\$ 640.67
\end{gathered}
$$

\begin{tabular}{|c|c|c|c|c|c|c|c|c|c|c|}
\hline & \multicolumn{10}{|c|}{ PROYECTADOS } \\
\hline & \multicolumn{2}{|c|}{$2018 p$} & \multicolumn{2}{|c|}{$2019 p$} & \multicolumn{2}{|c|}{$2020 p$} & \multicolumn{2}{|c|}{$2021 p$} & \multicolumn{2}{|c|}{$2022 p$} \\
\hline UTILIDAD OPERACIONAL & $\$$ & 100,00 & $\$$ & 110,00 & $\$$ & 121,00 & $\$$ & 129,00 & $\$$ & 135,00 \\
\hline$($ - ) Impuestos (33\%) & $-\$$ & 33,00 & $-\$$ & 36,30 & $-\$$ & 39,93 & $-\$$ & 42,57 & $-\$$ & 44,55 \\
\hline UTILIDAD OPERACIONAL NETA - NOPAT & $\$$ & 67,00 & $\$$ & 73,70 & $\$$ & 81,07 & $\$$ & 86,43 & $\$$ & 90,45 \\
\hline (+ ) Depreciaciones & $\$$ & 70,00 & $\$$ & 80,00 & $\$$ & 90,00 & $\$$ & 96,00 & $\$$ & 96,00 \\
\hline ( + ) Amortizaciones de gastos diferidos & $\$$ & 40,00 & $\$$ & 46,00 & $\$$ & 53,00 & $\$$ & 61,00 & $\$$ & 67,00 \\
\hline FLUJO DE CAJA OPERATIVO & $\$$ & 177,00 & $\$$ & 199,70 & $\$$ & 224,07 & $\$$ & 243,43 & $\$$ & 253,45 \\
\hline$(+/$ - ) Variación en capital de trabajo & $-\$$ & 10,00 & $-\$$ & 15,00 & $-\$$ & 12,00 & $-\$$ & 8,00 & $-\$$ & 4,00 \\
\hline$(+/-)$ Variación en activos fijos & $-\$$ & 60,00 & $-\$$ & 60,00 & $-\$$ & 60,00 & $-\$$ & 35,00 & $\$$ & \\
\hline FLUJO DE EFECTIVO LIBRE & $\$$ & 107,00 & $\$$ & 124,70 & $\$$ & 152,07 & $\$$ & 200,43 & $\$$ & 249,45 \\
\hline
\end{tabular}

$$
\text { FEL }=\text { Flujos de Efectivo Libres espera- }
$$
dos para los años $t$

$\mathrm{CPPC}=$ Costo promedio ponderado de capital (tasa de descuento)

ValorPresente del ValorResidual $=\Sigma \frac{\frac{F E L(t) *(1+g)}{C P P C-g}}{(1+C P P C) n}$

Tabla 3. Ejemplo de Flujos de Efectivo Libres proyectados

Fuente: Sosa (2014) 
$\mathrm{t}=$ Tiempo estimado de la empresa en años

A manera de ejemplo se presenta en la Tabla 3 este cálculo, partiendo de unos flujos de efectivo que se proyectan a 5 años, de acuerdo a Sosa (2014).

Paso 7: Cálculo del Valor Presente del Valor Residual o de continuidad de los Flujos de Efectivo Libres:

Este valor presente se calcula por la ecuación 6 (Armendáriz, 2012; Parra, 2013), así:

Donde:

FEL $=$ Flujo de Efectivo Libre en el periodo $\mathrm{n}+1$ (a partir de ese momento, se considerará creciente a una tasa de crecimiento $\mathrm{g}$ ).

$\mathrm{g}=$ Tasa de crecimiento (gradiente) a lar-

ValorPresente del ValorResidual $=\frac{\frac{F E L(t) *(1+g)}{C P P C-g}}{(1+C P P C) n}$

ValorPresente del ValorResidual $=\frac{\frac{\$ 249.45 *(1+0.05)}{0.0816-0.05}}{(1+0.0816) 5}$

ValorPresente del ValorResidual $=\frac{\frac{\$ 261.9225}{0.0316}}{(1.4802443)}$

ValorPresente del ValorResidual $=\frac{\$ 8288.69}{(1.4802443)}$

ValorPresente del ValorResidual $=\$ 5599.53$

go plazo (perpetuidad), que debe ser sostenible en el tiempo.

Autores como Revello (2014), Sequeda (2014) y Sosa (2014), expresan que la tasa de crecimiento a perpetuidad, debiera ser relativamente pequeña y no superior a la inflación o al crecimiento futuro de la economía del país donde desarrolla sus actividades, cuyo referente es el Producto Interno Bruto (PIB) y "estar en línea con el crecimiento del mercado y el nivel de competitividad del mismo" (Milla y Martínez, s.f., p. 36).

Si $\mathrm{g}=5 \%$, se tiene que:

En la página de internet del Banco de la República, en la sección de estadísticas ${ }^{4}$ está disponible la información histórica tanto de la inflación como del PIB. La misma información proyectada se puede encontrar en páginas de internet de los bancos que publican tablas con las proyecciones de los indicadores macroeconómicos a varios años.

Paso 8: Valor total de la empresa.

Una vez calculados los valores presentes tanto de los Flujos de Efectivo Libres como del Valor residual de los mismos flujos, se procede a sumarlos, así:

Valor Total de la Empresa $=V P(F E L+V R)$

Donde:

$\mathrm{VP}=$ Valor Presente

$\mathrm{FEL}=$ Flujo de Efectivo Libre

$\mathrm{VR}=$ Valor Residual

Dados los valores obtenidos anteriormente, el valor total de la empresa viene dado por:

Valor Total de la Empresa $=$ VP $($ FEL + VR $)$

Valor Total de la Empresa $=\$ 640.67+$ $\$ 5599.53$

Valor Total de la Empresa $=\$ 6240.20$

\section{Conclusiones y recomendaciones}

La determinación del valor de una compañía utilizando el modelo descrito en este tra- 
bajo, constituye una importante herramienta de gestión, tanto para los administradores como para los gerentes o propietarios de pequeñas y medianas empresas colombianas, el cual servirá de referente para verificar la maximización del valor de la empresa, con la generación de sus futuros flujos de efectivo, conforme a la definición y cumplimiento de sus objetivos organizacionales.

Aunque algunas veces el valor financiero de la Pyme puede ser un concepto subjetivo, debe acompañarse de la suficiente fundamentación teórica para que el resultado de rango de valores esté acorde con los intereses de ambas partes, en el momento de una negociación de una empresa. No se pretende que una sola cifra sea el valor exacto, verdadero y definitivo de una empresa. La obtención de un rango de valores, se convierte en un valor estimado, producto de un proceso objetivo que utiliza metodología financiera de flujos de efectivo para toma de decisiones.

Este trabajo está dirigido a los propietarios de pequeñas y medianas empresas colombianas que no cuenten con recursos suficientes para efectuar un adecuado proceso de valoración financiera de sus unidades de negocios, de una manera comprensible, sencilla y lo suficientemente justificada, de cara a una posible negociación que se quiera llevar a cabo; la fundamentación para valorar PyMEs no difiere de metodologías aplicables a grandes empresas y es aplicable para tomar decisiones responsables y efectivas, más aún cuando las PyMEs son importantes dentro del contexto del desarrollo económico del país, inclusive a nivel regional latinoamericano. Puentes (2013) las considera como "la piedra angular de toda economía y representan un papel importante en la producción industrial y de bienes y servicios" (p. 8) y esta importancia conlleva a que estas empresas muchas veces tengan las mismas necesidades financieras y específicamente de valoración de empresas, que las grandes compañías para su toma de decisiones. No por el hecho de tener un tamaño pequeño, deben dejar a un lado esta información y pasar desapercibida.

Si bien es cierto que existen varios métodos de valoración de empresas, son varios los autores que destacan la metodología de los flujos de efectivo descontados, por ser la más confiable y extendida, por su concepción metodológica, ya que se basa en la capacidad que tiene la empresa en marcha para generar ingresos futuros o flujos de efectivo, los cuales incrementarán su riqueza, independientemente de su tamaño, de las actividades que desarrolla o del sector al que pertenezca. La metodología basada en los flujos de efectivo descontado, tiene menos falencias que las presentadas por los métodos tradicionales (basados en el Estado de la Situación Financiera o en el Estado de Resultados).

Como menciona Damodaran (2012), hay que tener en cuenta tres aspectos por los cuales se puede afectar la estimación de los flujos de efectivo con las Pymes. El primero es que estos no consideran correctamente los salarios de los propietarios y no los diferencian de los ingresos que reciben como dividendos. El segundo, es la mezcla de los gastos e ingresos personales con los del negocio, que muchas veces no son medidos con precisión. El tercero, es el efecto de los impuestos individuales y los de la empresa, sobre el valor de la misma.

Con el fin de hacer lo más exacto posible el cálculo del valor financiero de la PyME, es importante acudir a fuentes de información financiera reales y confiables para el adecuado cálculo de la tasa de descuento a aplicar. En Colombia, se puede contar con la información suministrada por el Banco de la República, la Superintencia Financiera, la Superintendencia de Sociedades o la de páginas web de entidades financieras, que son de libre acceso y con una validez bastante alta.

En una valoración de empresas, se deberán estudiar cuidadosamente las posibilidades 
económicas requeridas por el futuro inversionista, pues están pueden ser bastante diferentes de las proyectadas por la empresa.

\section{Referencias bibliográficas}

AECA, Asociación Española de Contabilidad y Administración de Empresas (2004). Principios de valoración de empresas: Estudio de aplicabilidad de los diferentes métodos de valoración. Madrid, España: AECA.

AECA, Asociación Española de Contabilidad y Administración de Empresas (2005). Valoración de PYMES. Madrid, España: AECA.

Aguiar, I. (2014). Finanzas corporativas en la práctica. Madrid, España: Delta publicaciones.

Álvarez, R., García, K. y Borraez, A. (2006). Las razones para valorar una empresa y los métodos empleados. Semestre Económico, 9(18), 59-83.

Alzate, H. J. (2013). Gestión empresarial para PYMES. Medellín: Ediciones UNAULA.

Anzola, S. (2010). Administración de pequeñas empresas. México: Mc Graw Hill Educación.

Arias, L., Portilla, L. y Fernández, S. (2008). Metodología de valoración para empresas pequeñas. Scientia et Technica, 39, 269273.

Armendáriz, E. (2012). Modelos de valoración de empresas: un análisis crítico. Revista Ciencia UNEMI. 7, 74-87.

ASOBANCARIA, Asociacion Bancaria de Colombia (2017). La educación financiera como motor de las MiPYMEs en Colombia. Semana Económica 2017, 1094, 1-10.

Banco de la República (2018). Estadísticas del Banco de la República de Colombia. Bogotá, Colombia. Recuperado de:

http://www.banrep.gov.co/es/-estadisticas
Bedoya, O. C. (2000). Métodos de valoración de empresas. Medellín.

Beltrán, A., Torres, E., Camargo, R. y Bello, C. (2004). Pymes un reto a la competitividad. Bogotá: Universidad Externado de Colombia.

Block, S. y Hirt, G. (2008). Fundamentos de Administración Financiera. México: Mc Graw Hill.

Camargo, R. (2006). Mejorando la competitividad de la PYME: Desarrollo y aplicación de modelos de gestión. Bogotá: Universidad Externado de Colombia.

Cantalapiedra, M. (2000). Manual de gestión financiera para PyMEs. Madrid: Cie Dossat

Cañibano, L. y García, B. (2014). Algunas reflexiones sobre los métodos de valoración de empresas: Un modelo de valoración basado en la creación de valor. Revista Española de Capital Riesgo, 4, 3-14.

Castaño, J., Arias, L. y Portilla, L. (2011). Valoración financiera de empresas PyMES del subsector trilla de café en Colombia. Scientia et Technica, 47, 89-94.

Cayón, E. y Sarmiento, J. (2005). Modelo de valoración de empresas: Aspectos introductorios. Bogotá: Pontificia Universidad Javeriana.

Consejo Nacional de Política Económica y Social - CONPES (2007). Documento CONPES 3484. Bogotá.

Correa, J. A. y Jaramillo, F. (2007). Una aproximación metodológica y prospectiva a la gestión financiera en las pequeñas empresas. Contaduría Universidad de Antioquia, 50, 93-118.

Cruz, C. H. (2012). Medición y análisis de un modelo para la determinación del costo de capital de las PYMES del subsector de confección en Bogotá. Bogotá: Universidad Nacional. 
Damodaran, A. (2012). Investment valuation. Hoboken, New Jersey. John Wiley \& Sons.

Dumrauf, G.L. (2013). Finanzas corporativas. Un enfoque latinoamericano. Paraguay: Alfaomega Grupo Editor Argentino S.A.

Espinosa, J. (2008). La valoración de empresas en escenarios de incertidumbre. Económicas CUC, 29 (29), 211-218.

Federation des Experts ComptablesEuropeens FEE (2001). Business valuation: A guide for small and medium sized enterprises. Bruxelles: FEE.

Fernández, P. (2002). Valoración de empresas. Barcelona, España: Gestión 2000.

Filion, L. J., Cisneros, L. F. y Mejía-Morelos, J. H. (2011). Administración de PYMES. México: Pearson educación.

Fitó, A. (2015). ¿Cómo se valora una empresa? Barcelona, España: Editorial UOC.

Gamboa, J. (2003). Finanzas para sobrevivir: Un enfoque para la pequeña y mediana empresa. Bogotá: Alfaomega colombiana.

García, O. L. (2003). Valoración de empresas, gerencia del valor y EVA. Cali: Prensa moderna.

García, O. L. (2009). Administración financiera. Cali: Prensa moderna.

Garzón, F. J. y González, A. (2008). Valoración de una empresa de representaciones turísticas en Antioquia. Soluciones de postgrado EIA, 1, 83-91.

Gitman, L. y Zutter, C. (2012). Principios de Administración Financiera. México: Pearson Educación.

Gómez, A. (2005). Valoración de empresas con opciones reales. Cali, Colombia. Universidad Libre.
Gómez, R. (2014). Casos de valoración y adquisición de empresas. Madrid, España: Delta publicaciones.

González, J. y Medina, A. (2003). Valoración de empresas: Determinación del valor creado. Técnica Contable, 656, 13-23.

Jaramillo, F. (2010). Valoración de empresas. Bogotá: Ecoe ediciones.

Koller, T. Goedhart, M. y Wessels, D. (2010). Valuation: Measuring and managing the value of companies. New York. John Wiley \& Sons.

Labatut, G. (2005). El valor de las empresas: Métodos de valoración tradicionales y comparativos (múltiplos). Técnica Contable. 57(676), 18-31.

Labatut, G. (2006). El valor de las empresas: Métodos de valoración basados en el descuento de flujos. Técnica Contable. 58 (683), 11-24.

López, F.J. y Luna, W. (2001). Valoración de empresas en la práctica. Madrid, España: Mc Graw Hill Interamericana de España.

Martínez, C. E., Ledesma, J. S. y Russo, A.O. (2013). Particularidades del modelo de fijación de precios de activos de capital (CAPM) en mercados emergentes. Análisis Financiero, 121, 37-47.

Mascareñas, J. (2000). Fusiones y adquisiciones de empresas. Madrid, España: Mc Graw Hill Interamericana.

Milla, A. y Martínez, D. (s.f.). Valoración de Empresas por Flujos de Caja Descontados. Valencia, España: Altair consultores.

Narváez, A. (2009). Valoración de empresas: en busca del precio justo. Contabilidad y $\mathrm{Ne}$ gocios. 4(7), 23-30.

Ortiz, H. (2015). Análisis financiero aplicado y normas internacionales de información financiera - NIFF. Bogotá: Universidad Externado de Colombia. 
Parra, A. (2013). Valoración de empresas: Métodos de valoración. Revista Contexto, 2, 1-17.

Puentes, J.R. (2013). Las Pymes colombianas y las TIC: ¿panacea o ilusión? Bogotá: Editorial Temis.

Quemada, E. (2013). ¿Puedo comprar una empresa?: todo un mundo de posibilidades. Madrid, España: Ediciones Pirámide.

Revello, J. M. (2014). La valoración de los negocios: una guía teórica y práctica para valorar empresas. Madrid, España: Delta publicaciones.

Rojo, A. A. (2007). Valoración de empresas $y$ gestión basada en valor. Thomson Editores.

Saavedra, M. L. (2011). Herramientas de planeación financiera para las PYMES. México: Gasca.

Santandreu, P. y Torres, J. (2012). Selección del método de valoración de empresas en función de la empresa y el ciclo económico: El modelo QQC. Revista de contabilidad y dirección. 15, 115-132.

Sequeda, P. M. (2014). Finanzas corporativas $y$ valoración de empresas al alcance de todos. Bogotá: Ediciones de la U.

Sosa, M. C. (2014). Análisis fundamental para la valoración y la toma de decisiones. Bogotá: Alfaomega colombiana.

Tapia, G. (2013). Valuación de empresas: Un enfoque práctico y dinámico. México: Alfaomega grupo editor.

Tascón, M. T. (2002). De la valoración contable a la valoración financiera de la empresa. Contabilidad y Auditoría, 16, 53-64.

Trujillo, J. y Martínez, O. (2016). Matemáticas financieras y decisiones de inversión. Bogotá: Alfaomega.
Vargas, A. (2011). Estimación del costo del patrimonio y costo del capital por medio de tasas de rendimiento ajustadas al riesgo. Investigación \& Desarrollo, 11, 118-135.

Vargas, C. A. (2015). Prospectiva tecnológica como ventaja competitiva para la gestión financiera en las PyMEs. Redes de ingeniería, 6, 113-120.

Vélez, I. (2004). Decisiones de inversión: Enfocado a la valoración de empresas. Bogotá: Centro Editorial Javeriano.

Vélez, I. (2006). Decisiones de inversión: para la valoración financiera de proyectos $y$ empresas. Bogotá: Centro Editorial Javeriano.

Vidarte, J. J. (2009). El flujo de cada descontado como la mejor metodología en la determinación del valor de una empresa. Gestión y Desarrollo, 6(2), 103-110.

Zitzmann, W. (2009). Valoración de empresas con Excel: simulación probabilística. Bogotá: Alfaomega.

\section{Notas}

${ }^{1}$ Pyme: Acrónimo de Pequeña y Mediana Empresa, que de acuerdo a la Ley 905 de 2004, cuentan con un número de empleados entre 11 hasta 200 y con activos fijos por un valor entre 501 y 30.000 SMMLV.

2 Ambito.com en la sección: www.ambito.com/economia/mercados/ riesgo-pais/

${ }^{3}$ http://pages.stern.nyu.edu/ adamodar/

${ }^{4}$ www.banrep.gov.co/es/-estadisticas 
